\title{
Posterior segment involvelent in remote lightning strike
}

\author{
Atul Kumar Singh \\ Department of Ophthalmology Command Hospital (AF) Bangalore Karnataka, \\ India
}

\section{Introduction}

Some form of ophthalmic injury is seen in the majority of lightening victims. These may be anterior segment involvement, mostly the cornea. ${ }^{1}$ Other lesion on the anterior segment include uveitis, hyphaema, cataract and dislocated lens. ${ }^{2}$ Posterior segment lesion include vitreous haemorrhage, retinal oedema, retinal haemorrhage, retinal detachment, cystoids macular oedema, chorioretinalrupture, maculopathy, CRVO and CRAO. ${ }^{3}$ Neuro-ophthalmic lesion include loss of pupillaryreflex, anisocoria, horner syndrome, multiple cranial nerve palsies and nystagmus.

\section{Case report}

A 35 years old patient presented to us with sudden decrease in vision from right eye associated with hearing loss on that side. He gave the history of light falling on the right side of body one day back in the night as he stepped out from his house. As soon as he touched the ground in night around $11 \mathrm{pm}$ he experienced sharp electric current passing through his right side of body for fraction of second and soon after few hours he noticed some visual disturbance. His left side was uninvolved as his left side was covered by tin shade.

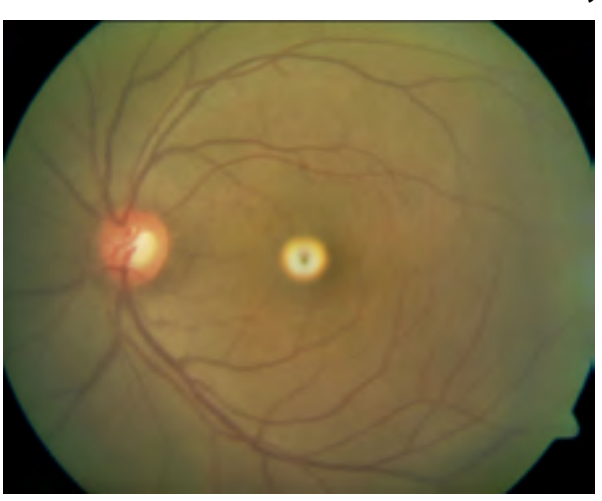

Fig 1. Left eye of patient

On examination his best corrected visual acuity was 6/18 / N/6 RE and 6/9/ $\mathrm{N} / 6$ in the LE.Anterior segment examination was within normal limits and intraocular pressure was $15 \mathrm{~mm}$ of $\mathrm{Hg}$ (both eyes). There was no RAPD. Fundus examination of left eye was within normal limits (Figure 1).Right eye fundus examination shows multiple retinal haemorrhages in all the quadrants with preretinal haemorrhage in the infero temporal area (Figure 2). His systemic examination (Blood pressure, Random Blood sugar) was normal. A

Correspondence: Atul Kumar Singh, Department of Ophthalmology Command Hospital (AF) Bangalore Karnataka, 560007, India E-mail:draksingh78@gmail.com 
comprehensive investigations failed to reveal any another underlying etiology (This include CBC CT,BT,INR,Homocysteine level,protein C and S, Antithrombin III and factor $V$ level).In the mean time he was also evaluated by ENT specialist where the diagnosis of moderate conductive hearing loss was made. Patient was subjected to CT scan to find out the cause of hearing loss. CT scan revealed opacification of the mastoid air cells consistent with hemorrhagic effusion with no fracture of bone. After three weeks of follow up the pre retinal haemorrhage was completely resolved and retinal haemorrhage was decreased in number (Figure 3). His visual acuity was improved to 6/12/ N/8 RE. Our patient did not suffer from any skin or eye lid burns.

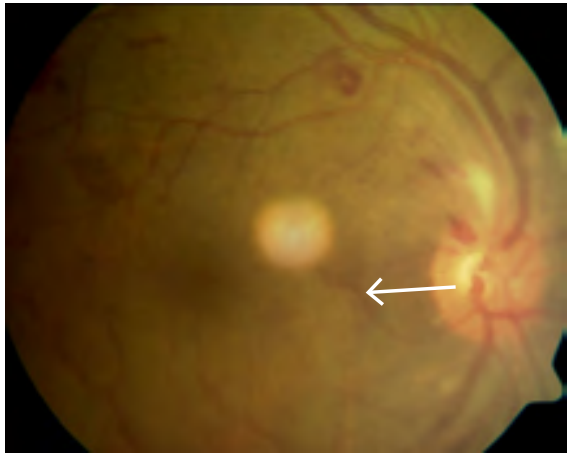

Fig 2. Right eye of patient multiple retinal haemorrhages in all the quadrants with pre retinal haemorrhage in the inferotemporal area

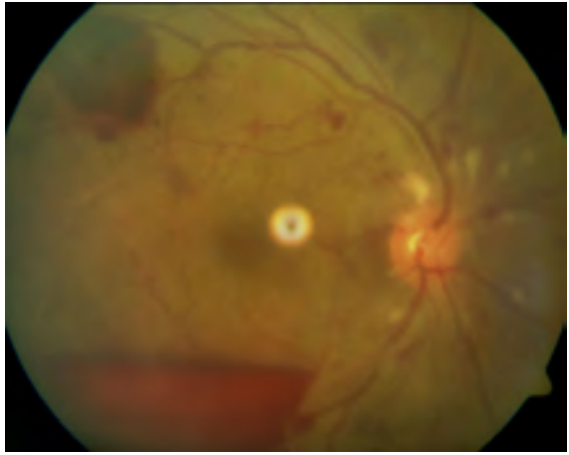

Fig 3. resolving haemorrhage

\section{Discussion}

Lee at $\mathrm{al}^{4}$ reported four routes by which lightning reaches the victim and causes injuries:

1. Direct strike: When the major current flows directly through the victim and is facilitated by metal object.

2. Splash: Where lightening strikes an object first and then arcs through the path of least resistance.

3. Contact: When lightning strike the object the victim is in contact with such as being while talking electrocuted over the phone or in bathtub by current flowing through wires or pipes

4. Ground current: The bolt strikes the ground and travels along the surface towards the victim

Our patient probably sustained the injury by the fourth mechanism mentioned ground current passing initially through the right side of the body indicated by loss of hearing in right ear, decreased vision RE due to posterior segment involvement.

Lightning involves a transfer of electric charge. Also lightning contact is instantaneous taking less time (exposure time usually lasts only 1 to 100 milliseconds) to 
cause injury. ${ }^{5}$ Tissue is destroyed by both heat and electrolysis. The high resistance offered by non-nervous tissue accounts for the thermal effects of electrical injuries, which result in immediate coagulation of the proteins of the cells. ${ }^{6}$ In the posterior segment macula is very sensitive to thermal damage because it contains high melanin granules of its RPE.The electric current damage the RPE also can damage the inner blood retinal barrier resulting in retinal vascular incompetence. ${ }^{7}$ Krishna et al. ${ }^{7}$ reported a case of bilateral macular hole with posterior sub capsular cataract. Handa et al. ${ }^{3}$ states that lack of posterior vitreous detachment and operculum support the diagnosis of lightening maculopathy as opposed to full thickness macular hole. He reported a case of maculpathy which initially presented as a retinal cyst with surrounding macular oedema and later evolved into full thickens macular hole.

Visual prognosis in patients with lightening injury will depend upon extent of involvement of ocular structure extent of macular damage and optic nerve involvement. In our case fortunately there is no involvement of macula and optic nerve resulting in very good visual prognosis of the patient.

\section{References}

1. Edelstein J, Peters W, Cartotto R. Lightning injury: A review and case presentations. Canadian J Plastic Sur. 1994;2:164-8.

2. Norman ME, Albertson D, Younge BR. Ophthalmic manifestations of lightning strike. Surv Ophthalmol. 2001;46:19-24.

3. Handa JT, Jaffe GJ. Lightning maculopathy. Retina. 1994;14:164-72

4. Lee MS, Gunton KB, Fischer DH, Brucker AJ. Ocular manifestations of remote lightning strike. Retina. 2002;22:808-10.

5. Dimick AR. Harrison's Principles of Internal Medicine. In: Fauci AS, Braunwald E, Isselbacher KJ, Wilson JD, Martin JB, Kasper DL, et al., editors. Health Professions Division. 14th ed. New York: McGraw-Hill; 1998. p. 2559.

6. Duke-Elder Sir S, Macfaul PA. In: System of Ophthalmology. Duke-Elder Sir S, editor. Vol XIV. London: Henry Kimpton; 1972. pp. 813-35. Part 2.

7. Krishna A Rao,Lavanya G Rao,Ajay N Kamath and VikramJain Indian J Ophthalmol. 2009 Nov-Dec; 57(6): 470-472. 